\title{
Research-based education as a model to change the teaching and learning environment in STEM disciplines
}

Isabel Huet ${ }^{\mathrm{a}}$

${ }^{a}$ Centre for Higher Education Research and Practice, Kingston University, Kingston upon Thames, United kingdom

Kingston University, Kingston Hill Campus, Kenry House, room 0031, KT2 7LB, email: i.huet@kingston.ac.uk 


\title{
Research-based education as a model to change the teaching and learning environment in STEM disciplines
}

\author{
This paper discusses the benefits and threats of promoting and reinforcing a \\ research-based education environment to STEM undergraduate students. The \\ paper explores the rationale for research-based education as a pedagogical driven \\ approach, where undergraduate students learn through enquiry and discovery. \\ Research evidence of a STEM case-study conducted in an English university is \\ then presented, which sheds light on how this institution and STEM research \\ active academics are fostering students' learning in a research-based education \\ environment, the constraints they face, and the pedagogical solutions they \\ propose to empower students' learning. The paper concludes with a set of \\ recommendations aimed to raise the research-based education environment of \\ STEM Faculties or Departments.
}

Keywords: research-based education; STEM education; teaching and research nexus; teaching quality.

\section{Introduction}

The training of STEM (Science, Technology, Engineering and Mathematics) professionals require the development of well qualified experts in their subject fields who are able to respond to the constant demands of the workforce both in industry or academia. STEM education has therefore the objective to equip students with the knowledge, skills, attitudes and competencies that will enable them to cope with the uncertainty of the knowledge society. A vast body of literature and reports in engineering education, for example, has pointed out the challenges for training the future engineers (Sheppard et al. 2008; Engineering 2005) and the importance of investing on quality teaching and learning and on scholarship for achieving this goal (Stice et al. 2000; Wankat et al. 2002; Froyd, Wankat, and Smith 2012; Streveler and Smith 2006). De Graff and Ravesteijn (2001) refer to the needs of modern society and the engineering profession for having more 'complete engineers', referred by the 
authors as engineers with sophisticated and practical knowledge of 'technology and society' (p. 420). For institutions and academics this has meant they have had to respond with designing programmes of study that also cover non-technical subjects such as social skills. Future STEM professionals are also required to demonstrate analytic and synthesizing capabilities, to be critical thinkers and to autonomously find solutions for the daily problems. We believe that educating the future generation of STEM professionals will include the holistic training of both technical and non-technical knowledge and skills in an environment that is student centred and where students learn through research, enquiry and discovery.

In this paper we advocate the importance of creating a research-based education environment where academics and students teach and learn through enquiry and research. This teaching and learning approach has been perceived as beneficial for promoting students' learning, interest and motivation in STEM disciplines (Wallin, Adawi, and Gold 2017; Bubou, Offor, and Bappa 2016; Hoskisson, Aldridge, and Bowater 2015; Weaver, Russell, and Wink 2008). A recent study by Rodenbusch et al. (2016) points to the long-term undergraduate student gains that result from early engagement in research experiences during their undergraduate courses, denominated as course-based-research. The authors present the benefits for students and institutions alike in terms of 'increasing students' graduating with a STEM degree and graduating within 6 years', regardless of 'students' gender, race/ethnicity, and first-generation in college status' (Rodenbusch et al. 2016, 7). Learning in a research environment where first year students engage in courses related to research methods and course-based research, with associated credits, has proved to be better than later research internships. Students begin to construct knowledge that is new to them, building an understanding of what it means to be a researcher, and finding solutions for problems. 
This paper starts by presenting a definition of the research-based education model and the teaching and learning approaches that can be used under such a model. This first part of the paper offers a theoretical framework that will be used to analyse the data that emerge from the empirical study. The paper also discusses how such a model can be challenging for academics in a university environment where there is a growing pressure for high quality teaching and research. Finally, the paper concludes with final considerations and recommendations aimed to raise the research-based environment of STEM Faculties or Departments. The recommendations were elaborated based on the data findings and on the literature review.

\section{Research-based education: the rationale}

The model explored in this paper sets the foundation for restructuring the pedagogical approach to teaching and learning in modern universities. The research-based education model is shaped by the Humboldt ideal of a university where research and teaching takes place side by side, and by Newman's ideal of useful and liberal knowledge where students are guided/supported to be a community of thinkers, able to 'think and to reason and to compare and to discriminate and to analyse' (Newman 2010, 256). The model is also shaped by European studies conducted by Griffiths (2004), Healey (2005), Healey and Jenkins (2009), Jenkins and Healey (2013), Visser-Wijnveen (2013), and US studies conducted by Rodenbusch et al. (2016), Auchincloss et al. (2014), and Lopatto and Tobias (2010).

Bringing teaching and research closely together is an ideal that originates from German universities in the early nineteenth-century. This ideal was led by the philosopher Humboldt, who believed the pursuit of (new) knowledge should be conducted by both academics and students, who would work side by side as coresearchers. This approach to knowledge construction takes place in a learning 
environment where research and inquiry inform teaching and vice versa. The Humboldt ideal of a research-based education is based on students' 'disinterested search of truth' (Haverhals 2007, 424) through the cultivation of 'pure' academic inquiry. This process of discovery was perceived as an end in itself, as a 'training of intellect' (Haverhals 2007), without a focus on the 'practical' activities (Renaut 1995), and without therefore being immediately 'useful' (Newman 2010). By engaging in the process of 'pure' inquiry individuals were educated to construct knowledge that would sustain the 'transformation of society from below and from within' (Haverhals 2007, 423), thereby serving the purpose of shaping individuals' character formation, and contributing to their holistic education as critical thinkers and responsible citizens.

In European post-modern universities, research and inquiry are not necessarily the same as in Humboldt's concept of a modern university. Research active academics are not always interested to spend time and effort in pedagogical innovations. In a Report produced for the National Research Council Board of Science Education, Fairweather (Fairweather 2008) refers to the resistance of STEM academics to adopting more effective teaching strategies. This derives, according to the author, from the perception STEM academics have that the teaching process is at odds with the research process, and that research is more interesting and more valued at their institutions.

Barnett suggests there are many pressures that are pulling research and teaching apart; "the twentieth century saw the university change from a site in which teaching and research stood in a reasonably comfortable relationship with each other to one in which they became mutually antagonistic' (2003, 157). Several authors (Brew 1999; Jenkins and Healey 2009; Jenkins 2004) suggest that research and teaching are not contradictory roles and should not be seen as such in more teaching or research-oriented universities in the UK. However, there are tensions that need to be overcome by 
institutions in order to foster links and not creating a 'false' marriage between research and teaching.

The research-based education model is represented in Figure 1. Knowledge construction, which includes the process of knowledge acquisition, reproduction and production, encompasses the principles of assimilation and accommodation explored by Piaget (1976). Undergraduate students begin to assimilate knowledge that is new to them; however, cognitive change and learning only take place when the knowledge that they assimilate is connected to previous knowledge, shaped by social interactions and experiences, and leads to a phase of perturbation and accommodation that is necessary for learning to take place. The cognitive developmental perspective emphasises that students should engage in discussion in which the cognitive conflict-perturbation phase is resolved and inadequate reasoning is modified, leading to a phase of accommodation (Piaget 1976).

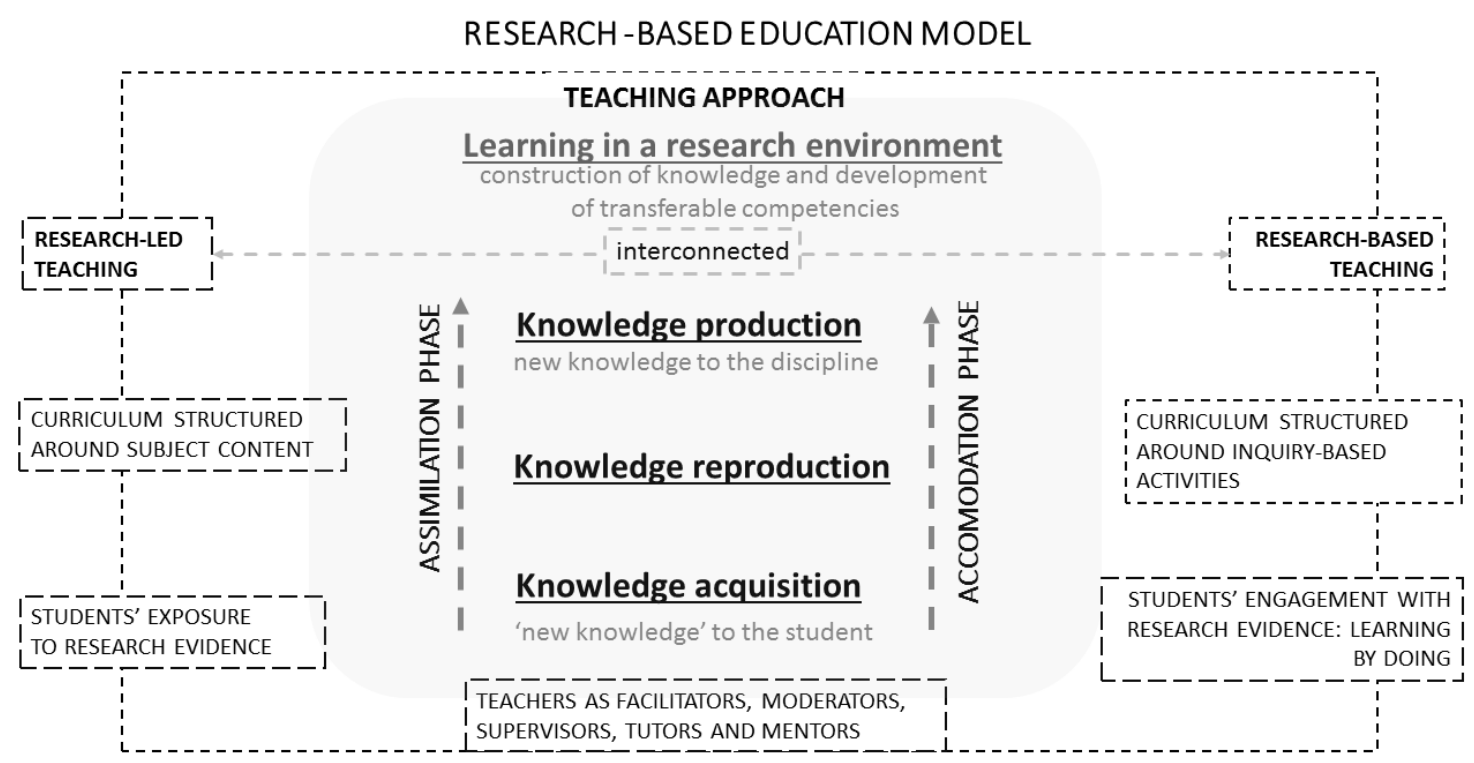

Figure 1: Research-based education model 
Constructivists, likeVygotsky, Piaget or Glasersfeld believed that students learn with each other in a social context and that the knowledge they construct is deeply influenced by the surrounding environment (Glasersfeld 1988, 1995; Piaget 1976; Kozulin 2003) . Following this theoretical concept, research-based education creates an environment that facilitates a culture where students learn by enquiring and searching for answers and solutions for problems in collaboration with others. This environment changes not only students, but also academics' conception of what is learning and teaching. Understanding the relevance of such an environment can be underlined by the thinking of Ceccato (as cited in Glasersfeld 1998, 28), the Italian pioneer of conceptual analysis, when he wrote that:

'The important thing is to show the child (and nothing changes if we substitute 'the student') the direction in which to go, to teach him to find his own path, to retrace it, and to continue it. Only in this way will he be able to assume a scientific attitude with which he can approach also the things of the mind.'

Students are constructing knowledge in a specific subject and they are also learning how to learn. Consequently, students are educated to become critical thinkers, lifelong learners, to acquire and reproduce knowledge that is new to themselves, and to progressively contribute to the creation of knowledge that may lead to enriching the knowledge of a disciplines(s). Following Newman's and Humboldt's philosophical thoughts, knowledge construction should not merely be seen as fulfilling the external purposes addressing the immediate needs of the economy, but as part of the development of an individual and contributing to their development as critical thinkers and agents of change in society. The purpose of research-based education is therefore important for the achievement of these goals. In this approach to education, academics can adapt different teaching approaches, which can be divided into research-led 
teaching and research-based teaching.

\section{Approaches to teaching and students' learning in a research-based education environment}

The research-led and research-based approaches to teaching presented in Figure 1 were initiated and then explored by Griffiths (2004), Healey (2005), Jenkins, Healey, and Zetter (2007) and Healey and Jenkins (2009). Research-led teaching occurs when academics use their expertise as active researchers or use the research of others to inform teaching, whilst their own research ideas and approaches are stimulated and sharpened through interactions with the students. The curriculum is structured around subject content and is based on the academics' research interests. This occurs by exposing students to research ideas and approaches, stimulating debate and provoking questions. Students can be either passive, by listening to the lecturer, or active, through participating in the discussions. Some research skills can also be developed, such as the ability to be involved in theoretical reflections/ discussions, and also the ability to make decisions and to justify options/perspectives. Academics can simultaneous deliver subject content, whilst facilitating and moderating a discussion. Academics do not need to be active researchers or be performing cutting edge research but they do need to be engaged in a scholarly manner within their disciplinary field.

Research-based teaching occurs when academics plan, deliver and assess students' work through their involvement in research or inquiry-based activities. The curriculum is therefore structured around these activities. Students learn about research

processes or learn through project oriented problems by developing research skills, such as the ability to critically analyse and reflect, to organise and plan, and to gather and 
analyse data. Consequently, academics act as supervisors, research tutors and research mentors.

These two approaches to teaching imply that students are constructing not only knowledge within a specific disciplinary field but also by developing a set of transferable skills, which will allow them to cope with the uncertainties of the knowledge society. Learning in a research-based education environment can help students to become more independent, autonomous and critical learners, who are able to succeed in a 'transdisciplinary world of learning' (Jackson and Ward 2004) and are prepared to adapt to new employment conditions and potential career shifts. This is in line with the 'Europe 2020 strategy' (Theodoropoulou 2010), which refers to the need for a strong European skilled workforce that should not only possess sustained knowledge in a specific disciplinary/scientific field but also a set of transferable skills that support sustainable growth. These competencies should start to be developed during the early educational stages and be strongly developed at the university level.

Learning in this environment contributes to the development of higher level cognitive skills and increases the responsibility for the students' own learning. Students start constructing knowledge that is new to themselves and develop skills that will bring them from the level of novice to expert learners (Dreyfus 2004). The objective of teaching is therefore supporting students to start thinking like expert scientists or engineers (Felder and Brent 2004). Academics can bring the basic principles of research (pure or applied) - for example, the process of discovery, the questioning of existing knowledge and the formulation of hypotheses - into their teaching by developing pedagogical strategies that are specifically designed to guide students to questioning their own knowledge and allow them to move into more complex stages of the learning development. By learning through enquiry and research, students move from a stage of 
'absolute knowing' (Magolda 1992), where they memorise and repeat knowledge, to a 'contextual knowing'. In this phase of intellectual development students recognise their contribution to knowledge and are able to judge and enquire new knowledge.

\section{Setting the Scene}

The case study is a STEM Faculty of a post 92 university situated in Southern England. These universities, often denominated in the UK as post 92 , were formerly polytechnics that converted to universities through the Further and Higher Education Act of 1992 (FHE, 1992). Despite the differences between these universities and more traditional universities, in terms of their mission and managerial procedures (Kok et al. 2010), there is one aspect we wish to highlight for the purpose of this paper, the academic identity of staff.

Macfarlane and Hughes argue that 'the teaching function, rather than research, is central to the academic identity at post-1992 universities' $(2009,9)$. Academics in these universities have been traditionally more oriented towards teaching related activities, and consequently have a heavier teaching workload. Nevertheless, the institution in this case study has undergone a considerable number of transformations, particularly in terms of its mission, the role of academic contracts, and career progression. A considerable number of academics have been hired on teaching and research-based roles, with new contracts being offered to staff with $\mathrm{PhDs}$ and considerable research experience. The majority of full time staff employed by the university have a focus on teaching and research (Table 1), and very few staff have solely research based contracts. The high number of hourly paid lecturers (HPLs) whose primary function is teaching remained quite high in 2014, although this situation is progressively changing. This aspect is further developed in data findings and discussion section. 
Table 1: Number of teaching and research contract staff in 2014

\begin{tabular}{llll}
\hline Academic employment function & Full time & Part-time & Total \\
\hline Teaching and Research & 650 & 271 & 921 \\
Research only & 46 & 25 & 71 \\
Teaching only - hourly paid lecturers & & 1151 \\
Hourly paid lecturers who have worked in the last twelve months & 680 \\
\hline
\end{tabular}

\section{Methodology}

This project follows an exploratory case-study design (Yin 1994) with an interpretative approach in order to address the two main research questions: (i) how is the research and teaching environment of a STEM Faculty engaging students to learn in a researchbased education environment?; and (ii) how are academics bringing their expertise/experience as researchers to develop pedagogical strategies that reinforce students' learning?

These research questions follow two theoretical propositions:

- Proposition 1: Research-based education is a valuable model to develop students' construction of knowledge, skills and attitudes, which will enable students to succeed in their studies and to cope with the uncertainty of a knowledge society (Rodenbusch et al. 2016; Brew 2010).

- Proposition 2: A strongly linked teaching and research culture leads to more motivated academics who can use their expertise/experience as researchers to add value to their students' education (Hajdarpasic, Brew, and Popenici 2013).

The case study represents a STEM Faculty of a post 92 University and the units of analysis are academics $(n=9)$ and Heads of School $(n=4)$ from STEM disciplinary areas, and senior managers of the institution $(n=3)$. The study followed a purposive sampling 
protocol to select academics that are research active in STEM disciplines. The study included five women and eleven men, with ages ranging from twenty-eight to fiftyeight, and positions ranging from lecturer to full professor.

\section{Procedure}

Data collection methods included three focus-groups with STEM academics, four interviews with Heads of School, three interviews with senior managers of the institution, and the textual analysis of documents, including education and research strategy 2015-2020 documents. Two scripts were prepared for the interviews; one for the research active academics and a second for the Heads of School and senior managers. Both the focus groups and the interviews commenced with a discussion related to two theoretical statements concerning the value and constraints of linking teaching and research. The objective was to provide academics with the opportunity to express their thoughts on some controversial aspects regarding the studies on the research and teaching nexus, and also to break the ice. One of the statements was:

'Courses taught by those at the cutting edge of research will necessarily be of higher quality than those taught by those merely using the research results of others - whatever the apparent quality of their style of delivery. (...) Furthermore, if teaching is undertaken by researchers the linkage is automatic, even if, as is often the case they are not always teaching about their own narrow research specialism.' (Lee 2004, 9)

The script of the interviews for the Heads of School and senior managers included questions related to the research and teaching environment culture of the School, Faculty or Institution, how the link between teaching and research is empowering students' learning (knowledge in a specific disciplinary field and the development of transferable skills), and the suggested institutional or school initiatives/actions that could be put in place to align the links between teaching and research. 
The script of the focus groups for academics included questions related to their own practice. The objective here was to understand if research-oriented academics were using their research expertise to develop pedagogical strategies that were sustained in a research-based or research-led teaching approach.

The raw data was analysed through a thematic analysis (Braun \& Clarke, 2006) using the software Nvivo $10^{\circledR}$, and the interviews were recorded with the consent of the participants and transcribed verbatim in order to facilitate the coding process. The first stage of the coding process followed a structural and initial coding exercise which allowed the first categorisation of the data corpus. During this process we identified large segments of texts on different topics (represented in the Nvivo $10^{\circledR}$ tree as the parent nodes). The second stage was to code each segment of data in more detail (Saldana 2009), and new codes emerged which formed the basis for the in-depth analysis. Two or more codes could be applied to the same passage of text as the data content can suggest multiple meanings that justify the use of more than one code. Simultaneous coding (Saldana 2009) is appropriate because 'social interaction does not occur in neat, isolated units' (Glesne and Peshkin 1992, 130).

Document analysis consisted of identifying statements highlighting the institutional strategy for boosting a university research-based teaching environment and/or bringing research and teaching more closely together in the Faculties or Schools.

The interviews were conducted between March and May 2014 and the documentary analysis was performed at the end of 2015 .

\section{Data Findings and Discussion}

The findings are organised based on the research questions posed, and data are triangulated according to the different data sources: individual interviews, focus-groups and documents. 


\section{Research question one: How is the research and teaching environment of a}

Faculty engaging students to learn in a research-based education environment?

\section{Faculty reinforcement of research-based education}

The Faculty reinforcement of research-based education is strongly shaped by the institutional research documents and the opening statement in the research document reinforces this:

'Research is critical to the University's distinctiveness, success and sustainability in an increasingly competitive higher education environment. It is central to the quality of our teaching and learning.'

The University's research strategy presents the objective of embedding research in all levels of academic activity, including undergraduate and postgraduate education. The actions more closely related to this objective are listed as:

- Implementation of the principle that all academic staff should engage in both teaching and research in order to share their first-hand knowledge and to enliven the taught content.

- To have research performance as a criterion in all new appropriate academic appointments.

- Ensuring that new starters, in order to satisfactorily complete their probation period, (i) show evidence of success and continuing progress in research, alongside enterprise and/or professional practice; (ii) have completed or be near to completion of a $\mathrm{PhD}$.

These actions had an impact on the type of academic contracts. The trend is now to hire STEM academics who are actively engaged in both teaching and research. Although the number of HPL contracts remained quite high in 2014 (see Table 1), the most recent data available (April 2016) points towards the tendency to have more staff on teaching 
and research contracts and less on teaching only contracts.

The three senior managers revealed an ideology for creating an institution where students and academics work side by side in a research-based education environment. They believe that students and academics learn much more in such an environment. Senior managers highlighted one initiative to bring students and staff as partners in research: the creation of the Integrated Research and Teaching Laboratory. This lab was launched on July 9th 2014, a space where students and lecturers can potentially work together on undergraduate or postgraduate final year projects or during Summer Research Internships. These "collaborative spaces" (Senior Manager B) are designed to assist students and academics to work together in a research environment. Another interviewee stated:

"As a post 92 university we are making an effort to create the conditions to support all staff who wants to do research and to create a research environment where students and lecturers learn collaboratively." (Senior Manager A)

The benefits for staff and student research partnerships are identified in the literature (Huet, van der Sluis and May 2016). According to Senior Manager A:

“these partnerships will boost students' confidence to carry out small research scale projects and to understand that doing research is not only targeted for academic researchers."

Senior manager B extended the benefits to the academics themselves. Researching in partnership with students, challenges academics to deconstruct the research objectives and procedures, and to communicate research outputs to a broader audience. According to this interviewee the opportunity to "explain research" to undergraduate students stimulates academics to think about new ways to communicate science.

The Faculty's strategies aim to boost a research environment that can potentially attract the interest of undergraduate students to study towards a Master's degree or a $\mathrm{PhD}$ and to pursue a career in STEM related areas, as well as creating a learning 
environment where students can construct knowledge that goes beyond their discipline, for example:

- Undergraduate Summer Research Internships, awarded on a competitive basis to well qualified students, provide penultimate year students with the opportunity to collaborate with a member of academic staff on a research project for eight weeks.

- There is a staff-student scheme that provides the opportunity for undergraduate students and staff to work as partners in educational research with the purpose of enhancing Black and Minority Ethnic (BME) students' learning experience whilst at university.

There is also a focus on the Engineering School to develop more applied research projects in collaboration with industry. According to the Head of School B, students and staff both gain through these collaborations. Links with industry, which are very strongly supported by the Faculty, will allow students to solve real problems and to undertake research on the best solutions to solve problems put forward by industry.

Impact of the research environment for quality teaching, students' learning and motivation

The research environment in the Faculty is perceived by all the three groups of participants (individual academics, Heads of School and senior managers), as being beneficial for teaching, but for most of the academics there was no clear evidence of how the research environment benefits undergraduate students' learning or the quality of the teaching. This data is in agreement with the findings of other studies which suggest there is not a direct link between a researcher who develops cutting edge research and quality teaching (Hattie and Marsh 1996; Gibbs and Habeshaw 2002). 
Quality research does not necessarily have an impact on the quality of teaching and as mentioned by six academics, the 'quality of the delivery' is far more important:

"I think that teaching is definitely better with research, but I still think it depends on the quality of delivery." (Academic C)

"You could be saving the world but actually teaching doesn't benefit from it (...). I don't care what your research is, if you cannot convey that message that's where everything collapses." (Academic G)

The three groups of participants believed that students feel more motivated and engaged in their activities when exposed to a research environment that brings them 'on board' with what is happening in terms of research. In contrast, the opportunity to bring research and teaching together helps academics to better conciliate what can often seem like two totally separate roles, that of teacher and researcher. Academics who have the opportunity to bring their research into the classroom and engage students in discussions (research-led teaching) reported higher levels of satisfaction and motivation for teaching, with some citing extraordinary research productivity. Teaching satisfaction is therefore fostered by their interest and motivation for research, as mentioned by two academics:

"I believe a colleague who engages in research will be passionate to teach/transmit that to the students. Being an active researcher will motivate him to teach as well. So teaching and research needs definitely to be linked and I don't perceive the role of an academic in HE to be different." (Academic C)

"I teach $X$, I have done research on that, it's much easier for me, I know what I am talking about, I have much more confidence. I think I can be more enthusiastic, I can change and keep adding things (...) they ask me something I know it, instead of saying I read in book written by Lawton in 1989." (Academic D)

Ultimately, a research-based education model places research and inquiry at the centre of teaching and learning, contributing to both students and academics' motivation and engagement. As Breen et al. (2003, p.x) highlighted: 
'(...) involving students in inquiry - in research - is a way of improving their learning, motivating them more. After all, what motivates large numbers of academics is engaging in the excitement of research. Bringing research and teaching together is a way of enhancing the motivation of both academics and students.'

\section{Research question two: How are academics bringing their expertise/experience as researchers to develop pedagogical strategies that reinforce learning in a research-based educational model?}

\section{Research and teaching conceptions}

The individual academics in this research agreed that students should learn in a research environment. In spite of the advantages of learning in a research environment, the academics believed that this is really only possible in the last year of undergraduate courses and is more evident in Masters programmes. The definition of research was perceived by most (7/9) as the process of knowledge creation, contributing to the advancement of science (pure research), or industry/society (applied research). The majority of the academics, with the exception of one, admitted that undergraduate students learn through inquiry ('active learning') and not via the research processes. Their conception of research is clearly aligned with the classic definition of research, which points towards a systematic investigative process employed to increase or revise current knowledge by discovering new facts. This is also aligned with the 'layer view' concept of research proposed by Breen et al. (2003), where the focus of research is on the data containing ideas together with (linked to) hidden meanings.

Research is interpreted as the process of discovering, uncovering or creating underlying meaning, and for most of the academics this is not possible to achieve with first or second year students, and is more difficult to achieve in the context of a post 92 university that receives students with low expectations concerning pursuing postgraduate research studies. By conceiving research in this way, this group of 
academics believe that they succeed in engaging students to learn in an inquiry environment in year three, when students are engaged in developing final year projects. Most of these projects are applied research projects that students develop in collaboration with the academics. Some of these projects involve research techniques or skills that are now starting to be developed in previous years, but the focus is not on the research methods but on the practical outcome of the project. For example,

"All our students have to do final year projects but very few of them do research related final year projects, many of them are just development or very practical and every year I offer research focused final year projects for my students and occasionally lead to publications so they are starting the whole process from literature review developing the research material and even writing the paper in the end." (Academic D)

Three academics perceived teaching as a process of delivery that needs to be informed by research, as presented in the section above. Good teachers are those who are able to pass/deliver their message, and this ability shapes a more or less effective teacher. This approach to teaching is highly aligned to the approach identified by Trigwell, Prosser, and Taylor (1994); a teacher-focused strategy with the intention that students acquire the concepts of the discipline. Nevertheless, four academics perceive teaching as a process of facilitating learning, which is more aligned to Trigwell, Prosser, and Taylor's (1994) alternative approach; a student-focused strategy aimed at students developing their conceptions. In this latter approach teachers are more focused on 'what the student is doing and learning than what the teacher is doing or covering' (Trigwell, Prosser, and Waterhouse 2007, 58).

\section{Research-based and research-led teaching approaches}

Figure 2 summarises the number of research-led and research-based activities stated by the different participants. 


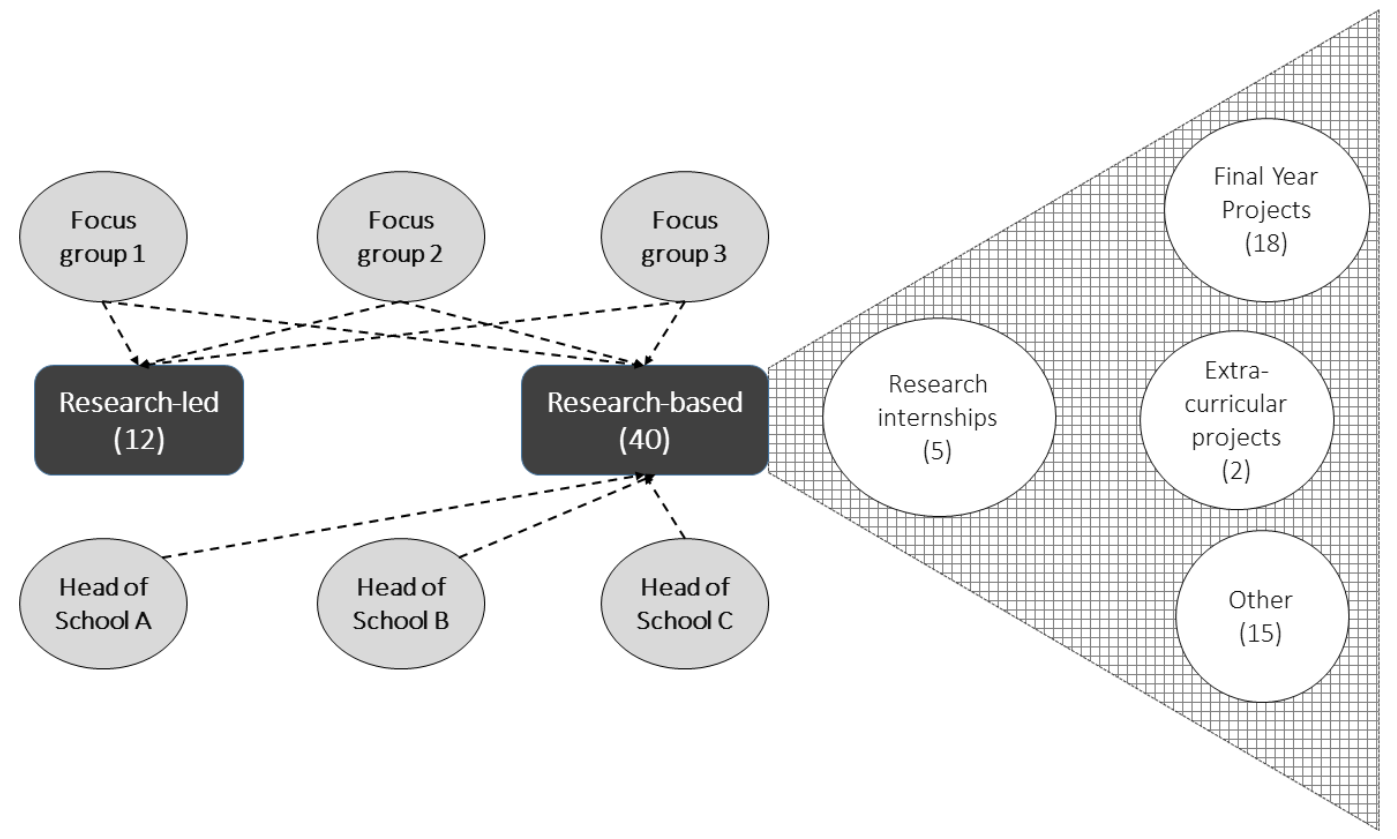

Figure 2: Summary of the number of research-led and research-based activities stated by the different participants.

Throughout the discussion during the focus-groups and individual interviews, the participants admitted to developing activities that are mostly linked to research-based teaching approaches, particularly related to final year projects (eighteen references), research internships (five references), extra-curricular projects (two references), and other (fifteen references). Research internships and extra-curricular projects are activities whereby students work alongside academics outside the formal curriculum, while during final year projects students develop research projects or applied projects based on, or informed by, academics' research (as part of the curriculum). The academics also mentioned that quite a lot of activities had been developed in postgraduate programmes (category 'other'), even if the focus of the interviews was at the level of undergraduate programmes.

One example of a research-based approach to teaching was:

"When our students do their projects in their third year, we have a very strong philosophy that it is their project and they define it, and we will give them advice as to whether it is a sensible sort of thing to try and do. 
But we don't come up with a list of projects (...). So having ideas seems to be quite important." (Academic F)

Research-led teaching approaches were only referred to twelve times. These were related to inviting guest speakers - industry experts, $\mathrm{PhD}$ students or researchers, to talk about their research findings with relevant impact for the subject being taught. Students were invited to discuss the research findings and make links to the work being done in the course. Two examples of research-led teaching approaches are presented below:

“(..) it's called a Nourish transfer partnership (...) I was able to invite people from the company to actually lecture students, it's just a short lecture but again it puts them into the right area. They get to hear directly from what is happening there, which they find very motivational." (Academic A)

"A good example is one colleague who has been doing very recent research related to the buildings that suffered damaged in the floods. He brings the data to the class so students can use that data to work in their own projects (...) at a later stage in the labs." (Senior Manager A)

Interestingly, many of the twelve examples provided by the academics were again linked to postgraduate programmes. This aligns with previous studies that suggest that the research and teaching relationship is stronger at the postgraduate than undergraduate level (Smeby 1998; Zaman 2004). The data findings point towards the predominance of teaching approaches that are linked to the curriculum design of many of the Faculty courses, namely the development of final year projects.

\section{Threats}

The threats identified in this study are linked to situational and dispositional factors (Heider, 1958), rather than disciplinary differences, and these factors shape academics' behaviour towards the development of a research-based education model as discussed above.

Two Heads of Schools criticised how the institutional discourse is not always easy 
to implement or to succeed in practice. The problems highlighted related to the lack of resources, particularly in terms of staff-student ratios:

"(...) the reality is that with very stretch resources, the policy doesn't always align with the resources to do that and I think that's one the constraint we are facing in the School $X$ and we have relatively large number of students per member of staff (...).” (Head of School A)

The same problem was also identified by two academics:

"But we have also moved things that sort of research methods content from second year to first year now because students have requested that. And I think over all I think it's a good thing in terms of student engagement but let's be honest it is massively more time consuming for staff. We haven't got any more staff and the same number of students." (Academic E)

The academics in this study did not perceive a fragmentation of research and teaching as advocated by previous studies (Smith and Rust 2011), but there was tension and concerns that were strongly influenced by the student-staff ratio, administrative and teaching workloads, and the lack of time for conducting both teaching and research effectively. Time was a key word in this study, as it was referred to 80 times during the focus-groups. The lack of time or the need for more time seems to be present in most of the academics' discourse, and this finding is in agreement with a previous study conducted by Pan, Cotton, and Murray (2014). Our findings reveal that STEM staff perceive teaching and research as equally important, and agreed that both activities should equally count for career progression, but all agreed research is still the most important activity for academic prestige and recognition. Four academics (4/9), would like to spend more time in research than teaching. This behavioural pattern, as suggested by Fairweather (2008) and Leslie (2002), holds true even when faculty members express a deep commitment to teaching and to their students. 


\section{Study limitations}

A limitation of this study is that it does not explore the impact that research centres/units may have on undergraduate students' learning. It would have been particularly interesting to understand how research centres, with their focused approach

to meeting the next Research Excellence Framework (REF) exercise, which is the system for assessing the quality of research in UK higher education institutions, engage undergraduate students in their research activities. Also, the study participants are not representative of the full staff body of this STEM Faculty. It would have been interesting to compare the views of staff who, in spite of being engaged in some form of scholarship, are not considered to be active researchers in their subject field. Nevertheless, this group of active researchers is certainly a good example of how academics bring their expertise as researchers to engage students to learn in a researchbased environment.

\section{Final Considerations and Recommendations}

This study, although exploratory in nature, provides a good understanding of how the research environment in a Faculty, as shaped by institutional policies, can foster a research-based educational model. There was clear evidence of a strong institutional commitment to raise the University's research and teaching quality profile, with the objective of boosting a research-based teaching culture. All the interviewees agreed that engaging students to learn in a research environment would be a good model to develop students' construction of knowledge, skills and attitudes, which will enable students to cope with the uncertainty of the knowledge society (proposition 1), and that a strongly linked teaching and research environment culture leads to more motivated academics who can use their expertise/experience as researchers to add value to their 
students' education (proposition 2).

The institutional mission and vision of this particular institution will be the changing agent for modelling the 'habitus' (Bourdieu 1984) where academics and students operate, and the identity of academics will be shaped by this environment. According to Clegg (2008), academics have the ability to shape their own identities as a result of institutional influences.

This research has highlighted the limited involvement students have in learning in a research-based education environment during the early stages of their undergraduate programmes, which reinforces the findings from previous studies (Smeby 1998; Zaman 2004). The majority of individual academics, with exception of one, believed that undergraduate students do not know what research is really about and have no idea how to be involved in research activities. Their conception of researchbased or research-led teaching is still much associated to the traditional definition of research: construction of new or applied knowledge. For most of the interviewees it is not perceived as a pedagogical approach to help students to learn in an enquiry or discovery mode, supporting students to develop research competencies that will facilitate their own learning process. According to five academics (5/9), students perceive research with the same lens: it represents an intangible reality intended for researchers or postgraduate students.

The successful development of a research-based education model needs to be discussed at the level of curriculum design with the course directors, individual academics, students, and when appropriate, with other stakeholders, such as professional bodies, industry or public sector organisations. A more flexible curriculum approach is needed if this particular institution wants to create course-based research 
(Corwin, Graham, and Dolan 2015), where discovery begins in the early years of undergraduate programmes.

Finally, the relationship between teaching and research can be shaped and differentiated by institution mission and strategies, the type of academic contracts offered, the level of teaching, and the nature of the disciplines (Zubrick, Reid, and Rossiter 2001; Leslie 2002), as well as by international or national educational policies (Brew 2010). These situational factors, alongside dispositional factors such individual personalities, intrinsic motivation, feelings, moods, and teaching and research abilities, can create the necessary conditions for the engagement or disengagement of academics in a particular approach to teaching. The threats identified in this paper, particularly in terms of the heavy teaching workload, the staff-student ratios and the perceived value of research for academic prestige and promotion shadow the motivation of academics for spending time in preparing research-based pedagogical activities. The time that could be allocated to these actions are in fact spent on teaching-related administrative work, meetings and engagement in pure or applied research. The perceived value of engaging STEM students in a research-based model is fundamental for training students to become self-regulated learners, critical thinkers and to pursue answers to a given problem.

\section{Recommendations}

The rationale and the data presented in this paper points towards a set of actions that can be implemented by STEM Departments or Faculties to boost, since early stages of undergraduate studies, a research-based education model. These actions are targeted against institutional policies (action 1 and 2), research and teaching culture (action 3) and pedagogic development (action 4). 
Action 1: Ensure effective institutional policies to reinforce synergies between units, committees and structures for teaching and research

Institutional policies must guarantee a more effective communication between education and research committees. The institution needs to embed in both the teaching and research strategies clear guidelines for embracing a research-based education model at all levels of study and both committees should convene, once every year, to discuss institutional priorities for next year. Institutional policies must guarantee planning and review processes that ensure the curriculum is shaped by this approach to teaching. All degree programmes should offer a coherent and progressive programme in learning how to do research in the discipline, leading to final year projects or dissertations, requiring significant research-related activities from the student.

Institutional mechanisms should be created to reward best practice. This could be achieved by providing incentives and rewards for academic staff to support undergraduate research and inquiry, particularly through workload planning (e.g. the appraisals should include a clear strategy on how academics are developing teaching strategies to engage students to learn in a research environment); institutional and departmental recruitment; criteria for appointment; performance review; or promotion processes.

Action 2: Ensure institutional policies to guarantee effective management of academics' 'time’ and staff-student ratios

Institutional policies must take into account the time needed to conceptualise, plan, and deliver research-based/led teaching approaches. Rather than asking academics to do more, institutions should consider how they can support academics within the time they 
have or by allowing them to buy extra time in certain circumstances. This might mean recruiting more staff to meet staff/student ratios. In particular, institutions should:

- Address teaching contracts by reinforcing the need for academics to be engaged in and at the forefront of new developments in pedagogic research, or allocate the time academics have available to be spent on research-based/led teaching activities;

- Provide more flexible administrative support to lighten the burden of academics and allocate more time to do 'what really matters', ie, teach and support students' learning;

- Make time for the production of pedagogic grant proposals, outputs and/or action research projects that inform the development of research-based or research-led teaching activities.

\section{Action 3: Raise the culture of research and teaching as two integrated activities}

STEM Faculties or Departments must be responsible for raising both students and academics' awareness of the research-based teaching model and reinforce the level of awareness of research activities being undertaken on campus and how this can be 'transmitted' to students. This can be done through the induction weeks by inviting second or third year students to explain to first years the rationale of learning and teaching in such an environment. Raising a research and teaching culture can be achieved, for example, by communicating the research expertise of STEM academics and the partnerships with industry related to knowledge transfer and innovation or by creating the opportunity for undergraduates to have contact with research labs. This contact might be different according to the level of study, the availability of labs and 
their researchers, and the level of commitment/engagement from each School or Department.

Schools or Departments must guarantee the communication with undergraduate and postgraduate students by creating spaces where they can interact. For example, all undergraduate students should have the possibility of participating in informal meetings with PhD students where they talk about their research, the research methods being used, the outputs of research and their life trajectories from undergraduate to postgraduate students. Another strategy is to bring research into the classroom. Every time a new module starts all academics involved and/or invited researchers should dedicate one session to present their own research and outputs, and how this can inform the subject covered. Research communication needs to be targeted to a non-specialist audience avoiding unnecessary jargon and keeping in mind the level of the programme.

\section{Action 4: Provide pedagogic support to academics}

The pedagogic support plays a crucial role on preparing academics to design teaching strategies that are truly reinforcing students to learn in a research or inquiry environment. Data findings from this study indicate academics perceive research as the construction of new or applied knowledge that can only be conducted by students who are in the last year of undergraduate programmes or registered on postgraduate programmes. The objective is therefore to train academics to develop learning and teaching strategies that are sustained in research-led or research-based approaches since early stages. It is important to create spaces for formal and informal discussion and interaction (e.g. workshops or seminars) where academics can discuss these approaches to teaching without being 'judged' by their practice, but rather supported by more experienced colleagues. Teaching should not be just seen as content delivery but also as 
engaging students in more active learning approaches by looking and selecting information, putting forward questions or being able to solve problems in a more autonomous way. In summary, the pedagogic training should address the following objectives:

- Raise awareness of the research-based education model, the advantages for students' learning and threats;

- Discuss the impact of such a model for the university and staff involved;

- Explore and reflect on different teaching and learning strategies. For example, (i) incorporating learning activities that promote discussion about research outcomes and methods; (ii) incorporating a 'thinking aloud' session on problems that arise from reading a paper or book chapter; or (iii) fostering the search and selection of information instead of giving students a comprehensive list of bibliography.

\section{Disclosure statement}

No potential conflict of interest was reported by the authors.

\section{References}

Auchincloss, Lisa Corwin, Sandra L Laursen, Janet L Branchaw, Kevin Eagan, Mark Graham, David I Hanauer, Gwendolyn Lawrie, et al. 2014. "Assessment of Course-Based Undergraduate Research Experiences: A Meeting Report.” CBELife Sciences Education 13 (1): 29-40. doi:10.1187/cbe.14-01-0004.

Barnett, R. 2003. Beyond All Reason: Living with Ideology in the University. Srhe Series. Society for Research into Higher Education \& Open University Press. Bourdieu, Pierre. 1984. Distinction: A Social Critique of the Judgement of Taste. Harvard University Press.

Braun, Virginia, and Victoria Clarke. 2006. Using thematic analysis in psychology. Qualitative Research in Psychology, 3(2), 77-101. 
Breen, Rosanna, Angela Brew, Alan Jenkins, and Roger Lindsay. 2003. Reshaping Teaching in Higher Education: A Guide to Linking Teaching with Research. Routledge.

Brew, Angela. 1999. "Research and Teaching: Changing Relationships in a Changing Context." Studies in Higher Education 24 (3): 291-301. doi:10.1080/03075079912331379905.

—. 2010. "Imperatives and Challenges in Integrating Teaching and Research." Higher Education Research \& Development 29 (July): 139-50. doi:10.1080/07294360903552451.

Bubou, Gordon Monday, Ibebietei Temple Offor, and Abubakar Saddiq Bappa. 2016. "Why Research-Informed Teaching in Engineering Education? A Review of the Evidence.” European Journal of Engineering Education, March. Taylor \& Francis, 1-13. doi:10.1080/03043797.2016.1158793.

Clegg, Sue. 2008. “Academic Identities under Threat?” British Educational Research Journal 34 (3). Taylor \& Francis: 329-45.

Corwin, Lisa A, Mark J Graham, and Erin L Dolan. 2015. "Modeling Course-Based Undergraduate Research Experiences: An Agenda for Future Research and Evaluation.” CBE-Life Sciences Education 14 (1). doi:10.1187/cbe.14-10-0167.

De Graaff, Erik, and Wim Ravesteijn. 2001. “Training Complete Engineers: Global Enterprise and Engineering Education.” European Journal of Engineering Education 26 (4). Taylor \& Francis: 419-27.

Dreyfus, Stuart E. 2004. "The Five-Stage Model of Adult Skill Acquisition.” Bulletin of Science, Technology \& Society 24 (3): 177-81.

Engineering, National Academy of. 2005. Educating the Engineer of 2020: Adapting Engineering Education to the New Century. Washington, DC: The National Academies Press. doi:10.17226/11338.

Fairweather, James. 2008. "Linking Evidence and Promising Practices in Science, Technology, Engineering, and Mathematics (STEM) Undergraduate Education." Board of Science Education, National Research Council, The National Academies, Washington, DC.

Felder, Richard M., and Rebecca Brent. 2004. "The Intellectual Development of Science and Engineering Students. Part 1: Models and Challenges." Journal of Engineering Education 93 (4). Blackwell Publishing Ltd: 269-77. 
Froyd, Jeffrey E, Phillip C Wankat, and Karl A Smith. 2012. "Five Major Shifts in 100 Years of Engineering Education.” Proceedings of the IEEE 100 (Special Centennial Issue). IEEE: 1344-60.

Further and Higher Education Act 1992 (UK). Available at:

https://www.legislation.gov.uk/ukpga/1992/13/contents [Accessed 5 Apr. 2016].

Gibbs, G., and T. Habeshaw. 2002. Recognising and Rewarding Excellent Teaching. Open Unive. Milton Keynes.

Glasersfeld, Ernst von. 1988. "The Reluctance to Change a Way of Thinking." The Irish Journal of Psychology 9 (1). Taylor \& Francis: 83-90.

Glasersfeld Ernst. von. 1995. “A Constructivist Approach to Teaching.” In

Constructivism in Education, edited by Steffe L. P. \& Gale J., 3-15. Erlbaum.

Available at: Hillsdale. http://www.vonglasersfeld.com/172 [Accessed 7

November 2017]

1998. “Cognition, Construction of Knowledge and Teaching.” In

Constructivism in Science Education: A Philosophical Examination, edited by

M R Matthews, 11-30. Springer Netherlands.

https://books.google.co.uk/books?id=Vo5qCQAAQBAJ.

Glesne, Corrine, and Alan Peshkin. 1992. Becoming Qualitative Researchers: An Introduction. Longman White Plains, NY.

Griffiths, Ron. 2004. "Knowledge Production and the Research-teaching Nexus: The Case of the Built Environment Disciplines." Studies in Higher Education 29 (6): 709-26. doi:10.1080/0307507042000287212.

Hajdarpasic, Ademir, Angela Brew, and Stefan Popenici. 2013. "The Contribution of Academics' Engagement in Research to Undergraduate Education." Studies in Higher Education 40 (4): 644-57. doi:10.1080/03075079.2013.842215.

Hattie, John, and Herbert W Marsh. 1996. "The Relationship between Research and Teaching: A Meta-Analysis." Review of Educational Research 66 (4). Sage Publications: 507-42.

Haverhals, Barbara. 2007. "The Normative Foundations of Research-Based Education: Philosophical Notes on the Transformation of the Modern University Idea." Studies in Philosophy and Education 26 (5): 419-32. doi:10.1007/s11217-0079053-3.

Healey, Mick. 2005. "Linking Research and Teaching Exploring Disciplinary Spaces and the Role of Inquiry-Based Learning." In Reshaping the University: New 
Relationships between Research, Scholarship and Teaching., edited by R Barnett, 67-78. Open university Press. http://www.delta.wisc.edu/events/bbb balance healey.pdf.

Healey, Mick, and Alan Jenkins. 2009. Developing Undergraduate Research and Inquiry. HEA.

Heider, Fritz. 1958. "Interpersonal relations." New YorN: Wiley (1958)

Hoskisson, Paul A, Philip Aldridge, and Laura Bowater. 2015. "Inspiring STEM Undergraduates to Tackle the AMR Crisis.” FEMS Microbiology Letters 362 (18). The Oxford University Press: fnv138.

Huet, Isabel, Hendrik van der Sluis, and Steve May. 2016. Staff-student partnerships in pedagogic research: the benefits for students' development of research competencies. Proceedings of the 9th International Conference of Educational Research and Innovation (ICERI) (pp. 3232-3241), Seville, Spain.

Jackson, Norman, and Rob Ward. 2004. "A Fresh Perspective on Progress Files - a Way of Representing Complex Learning and Achievement in Higher Education." Assessment \& Evaluation in Higher Education 29 (October): 42349.

Jenkins, Alan. 2004. A Guide to the Research Evidence on Teaching-Research Relations. Higher Education Academy York.

Jenkins, Alan, and Mick Healey. 2009. Institutional Strategies to Link Teaching and Research. HEA. http://www.ipd.gu.se/digitalAssets/1345/1345048_institutional_strategies.pdf.

—. 2013. "Research-Led or Research-Based Undergraduate Curricula." In University Teaching in Focus : A Learning-Centred Approach, edited by Lynne Hunt and Denise Chalmers, 128-44. Abingdon, Oxon: Routledge.

Kok, Seng-Kiat, Alex Douglas, Bob McClelland, and David Bryde. 2010. "The Move Towards Managerialism: Perceptions of Staff in 'traditional' and 'new' UK Universities." Tertiary Education and Management 16 (2): 99-113. doi:10.1080/13583881003756740.

Lee, Roger. 2004. "Research and Teaching: Making or Breaking the Links?" Planet 12 (1). Taylor \& Francis: 9-10.

Leslie, David W. 2002. "Resolving the Dispute: Teaching Is Academe's Core Value." Journal of Higher Education. JSTOR, 49-73. 
Lopatto, David, and Sheila Tobias. 2010. Science in Solution: The Impact of Undergraduate Research on Student Learning. Council on Undergraduate Research.

Macfarlane, Bruce, and Gwyneth Hughes. 2009. “Turning Teachers into Academics? The Role of Educational Development in Fostering Synergy between Teaching and Research." Innovations in Education and Teaching International 46 (1): 514. doi:10.1080/14703290802646214.

Magolda, Marcia B Baxter. 1992. Knowing and Reasoning in College: Gender-Related Patterns in Students' Intellectual Development. Jossey-Bass.

Newman, J H. 2010. Discourses on the Scope and Nature of University Education: Addressed to the Catholics of Dublin. Cambridge Library Collection Education. Cambridge University Press. https://books.google.co.uk/books?id=bi2CdwEjRMMC.

Pan, Wei, Debby Cotton, and Paul Murray. 2014. "Linking Research and Teaching: Context, Conflict and Complementarity." Innovations in Education and Teaching International 51 (1). Routledge: 3-14. doi:10.1080/14703297.2013.847794.

Piaget, Jean. 1976. "Piaget and His School: A Reader in Developmental Psychology." In , edited by Bärbel Inhelder, Harold H Chipman, and Charles Zwingmann, 1123. Berlin, Heidelberg: Springer Berlin Heidelberg. doi:10.1007/978-3-64246323-5_2.

Renaut, Alain. 1995. “Les Révolutions de L’université.” Essai Sur La Modernisation de La Culture. Paris: Calmann-Lévy. JSTOR.

Rodenbusch, Stacia E, Paul R Hernandez, Sarah L Simmons, and Erin L Dolan. 2016. "Early Engagement in Course-Based Research Increases Graduation Rates and Completion of Science, Engineering, and Mathematics Degrees." CBE-Life Sciences Education 15 (2). doi:10.1187/cbe.16-03-0117.

Saldana, Johnny. 2009. The Coding Manual for Qualitative Researchers. Sage Publications.

Sheppard, Sheri D, Kelly Macatangay, Anne Colby, and William M Sullivan. 2008. Educating Engineers: Designing for the Future of the Field. Vol. 2. JosseyBass. 
Smeby, Jens-Christian. 1998. "Knowledge Production and Knowledge Transmission. The Interaction between Research and Teaching at Universities." Teaching in Higher Education 3 (1): 5-20. doi:10.1080/1356215980030101.

Smith, Pete, and Chris Rust. 2011. "The Potential of Research-based Learning for the Creation of Truly Inclusive Academic Communities of Practice." Innovations in Education and Teaching International 48 (2). Taylor \& Francis: 115-25.

Stice, James E, Richard M Felder, Donald R Woods, and Armando Rugarcia. 2000.

"The Future of Engineering Education. IV. Learning How to Teach." Chemical Engineering Education 34 (2): 118-27.

Streveler, Ruth A, and Karl A Smith. 2006. "Conducting Rigorous Research in Engineering Education.” Journal of Engineering Education 95 (2). Blackwell Publishing Ltd: 103-5.

Theodoropoulou, Sotiria. 2010. "Skills and Education for Growth and Well-Being in Europe 2020: Are We on the Right Path.” EPC Issue Paper, no. 61.

Trigwell, Keith, Michael Prosser, and Philip Taylor. 1994. "Qualitative Differences in Approaches to Teaching First Year University Science.” Higher Education 27 (1): 75-84. doi:10.1007/BF01383761.

Trigwell, Keith, Michael Prosser, and Fiona Waterhouse. 2007. "Relations between Teachers 'Approaches to Teaching and Students 'Approaches to Learning," $57-70$.

Kozulin, Alex. 2003. Vygotsky's Educational Theory in Cultural Context. Cambridge University Press.

Visser-Wijnveen, G. J. 2013. "Vormen van de Integratie van Onderzoek En Onderwijs. [Forms of the Integration of Research and Teaching]." In Integratie van Onderzoek in Het Hoger Onderwijs. Effectieve Inbedding van Onderzoek in Curricula [Integration of Research in Higher Education. Effective Embedding of Research into the Curriculum], edited by \& J. M. H. M. Willems (eds) D. M. E. Griffioen, G. J. Visser-Wijnveen, 61-74. Groningen, The Netherlands: Noordhoff Uitgevers.

Wallin, Patric, Tom Adawi, and Julie Gold. 2017. "Linking Teaching and Research in an Undergraduate Course and Exploring Student Learning Experiences.” European Journal of Engineering Education 42 (1). Taylor \& Francis: 58-74. doi:10.1080/03043797.2016.1193125. 
Wankat, Phillip C, Richard M Felder, Karl A Smith, and Frank S Oreovicz. 2002. "The Scholarship of Teaching and Learning in Engineering." Disciplinary Styles in the Scholarship of Teaching and Learning: Exploring Common Ground. Washington, USA, AAHE/Carnegie Foundation for the Advancement of Teaching, 217-37.

Weaver, Gabriela C, Cianán B Russell, and Donald J Wink. 2008. "Inquiry-Based and Research-Based Laboratory Pedagogies in Undergraduate Science.” Nature Chemical Biology 4 (10). Nature Publishing Group: 577-80.

Yin, Robert K. 1994. Case Study Research. Design and Methods. Sage Publications.

Zaman, Mohammad Quamar uz. 2004. "Review of the Academic Evidence on the Relationship Between Teaching and Research in Higher Education." Research in Higher Education. doi:ISBN 1844781623.

Zubrick, Ann, Ian Reid, and Paul L Rossiter. 2001. Strengthening the Nexus between Teaching and Research. Vol. 6499. Citeseer. 